\title{
Chronic Glibenclamide Treatment Attenuates Walker-256 Tumour Growth in Prediabetic Obese Rats
}

\author{
Claudinéia Conationi da Silva Franco ${ }^{a}$ Carina Previate ${ }^{a}$ \\ Kátia Gama de Barros Machado ${ }^{a}$ Silvano Piovan ${ }^{b}$ Rosiane Aparecida Mirandac \\ Kelly Valério Prates ${ }^{a}$ Veridiana Mota Moreira ${ }^{a}$ Júlio Cezar de Oliveirad \\ Luiz Felipe Barella ${ }^{e}$ Rodrigo Mello Gomes ${ }^{f}$ Flávio Andrade Francisco ${ }^{a}$ \\ Isabela Peixoto Martins ${ }^{a} \quad$ Audrei Pavanello ${ }^{a}$ Tatiane Aparecida Ribeiro ${ }^{a}$ \\ Laize Peron Tófolo ${ }^{a}$ Ananda Malta ${ }^{a}$ Aline Amenencia de Souza ${ }^{a}$ \\ Vander Silva Alves ${ }^{a}$ Sandra da Silva Silveira ${ }^{a} \quad$ Maria Raquel Marçal Natalis \\ Jean Carlos Fernando Besson ${ }^{9}$ Hely de Morais ${ }^{h}$ Helenir Medri de Souzah \\ Juliane Rocha de Sant Annai Marialba Avezum Alves de Castro Pradoi \\ Paulo Cezar de Freitas Mathias ${ }^{a}$
}

aLaboratory of Secretion Cell Biology, Department of Biotechnology, Genetics and Cell Biology, State University of Maringá - Maringá/PR, Brazil, bLaboratory of Physiology, Department of Physiological Sciences, State University of Maringá - Maringá/PR, 'Carlos Chagas Filho Biophysics Institute, Federal University of Rio de Janeiro, Rio de Janeiro/RJ, 'Institute of Health Sciences, Federal University of Mato Grosso - Sinop/MT, Brazil; eMolecular Signaling Section, Laboratory of Bioorganic Chemistry, National Institute of Diabetes and Digestive and Kidney Diseases, National Institutes of Health, Bethesda, MD, USA; fLaboratory of Neuroscience and Cardiovascular Physiology, Department of Physiological Sciences, Federal University of Goiás - Goiânia/GO, פLaboratory of Animal Histology, Department of Morphological Sciences, State University of Maringá - Maringá/PR, hLaboratory of Metabolic Physiology, Department of Physiological Sciences, State University of Londrina - Londrina/ PR, 'Laboratory of Mutagenesis \& Genetics, Department of Cell Biology and Genetics, State University of Maringá - Maringá/PR, Brazil

\section{Key Words}

Diabetes • Glibenclamide • Walker-256 tumour • Prediabetic rats

\footnotetext{
Abstract

Background/Aims: The sulphonylurea glibenclamide (Gli) is widely used in the treatment of type 2 diabetes. In addition to its antidiabetic effects, low incidences of certain types of cancer have been observed in Gli-treated diabetic patients. However, the mechanisms underlying this observation remain unclear. The aim of the present work was to evaluate whether obese adult rats that were chronically treated with an antidiabetic drug, glibenclamide, exhibit resistance to rodent breast carcinoma growth. Methods: Neonatal rats were treated with monosodium C.C. da Silva Franco and C. Previate contributed equally to this work.

\begin{tabular}{ll}
\hline Dra. Claudinéia C. S. Franco & Building H67, room 19, State University of Maringá/ UEM - Colombo Avenue 5790, \\
& $87020-900$, Maringá/ PR (Brazil) \\
& Tel. / Fax + 55 (44) 3011 4892, E-Mail clauconationi@gmail.com
\end{tabular}
}


da Silva Franco et al.: Sulphonylurea Attenuates Walker Tumour Growth

L-glutamate (MSG) to induce prediabetes. Control and MSG groups were treated with Gli ( $2 \mathrm{mg} / \mathrm{kg}$ body weight/day) from weaning to 100 days old. After Gli treatment, the control and MSG rats were grafted with Walker-256 tumour cells. After 14 days, grafted rats were euthanized, and tumour weight as well as glucose homeostasis were evaluated. Results: Treatment with Gli normalized tissue insulin sensitivity and glucose tolerance, suppressed fasting hyperinsulinaemia, reduced fat tissue accretion in MSG rats, and attenuated tumour growth by $27 \%$ in control and MSG rats. Conclusions: Gli treatment also resulted in a large reduction in the number of PCNA-positive tumour cells. Although treatment did improve the metabolism of pre-diabetic MSG-rats, tumour growth inhibition may be a more direct effect of glibenclamide.

\section{Introduction}

Obesity is a worldwide epidemic that is closely associated with non-communicable diseases (NCDs) and leads to a huge impact on health systems. Cardiovascular diseases (CVD), cancers, diabetes and respiratory diseases are the main chronic diseases linked to obesity, contributing to a great number of deaths $[1,2]$. Among these diseases, type 2 diabetes is one of the most prevalent NCDs. Beyond its association with obesity, diabetes is also related to several types of cancer, including cancer of the kidney, bladder, pancreas, liver, breast, colon, endometrium and rectum [1,3-5]. The association between type 2 diabetes and cancer is well known.

Diabetic patients have a high propensity to develop cancer due to metabolic alterations, such as hyperinsulinaemia and hyperglycaemia, or even drugs that affect the cell cycle, which may contribute to mechanisms promoting cancer initiation or progression [6, 7]. Nevertheless, the role of metabolic dysfunctions, such as hyperinsulinaemia, which might induce cell proliferation and the consequent increased risk for cancer development, remains incompletely understood $[3,6]$.

Gli is an oral antidiabetic drug in a class of medications known as sulphonylureas, which have been widely used for 6 decades in the treatment of type 2 diabetes mellitus. Gli is a secretagogue agent that blocks ATP-dependent potassium channels $\left(\mathrm{K}_{\mathrm{ATP}}\right)$ after binding to a receptor located on the beta cell plasma membrane, allowing pancreatic beta cells to depolarize and leading to the opening of voltage-gated calcium $\left(\mathrm{Ca}^{+2}\right)$ channels, promoting an increase in the cytoplasmic $\mathrm{Ca}^{+2}$ concentration and subsequent stimulation of the exocytosis of insulin-containing granules. The increased insulin levels reduce hyperglycaemia in diabetic patients, improving their health condition $[7,8]$.

Epidemiological studies have demonstrated a low incidence of certain types of cancer in diabetic patients given antidiabetic therapies; however, the mechanisms underlying this association are still unclear. Gli may inhibit tumour growth directly or may act through its ameliorating effects on metabolism. [7, 9]. Furthermore, the lack of experimental studies showing the anticancer long-term effects of Gli makes it difficult to understand its effects.

The experimental model of obesity used in this work was generated by early postnatal administration of monosodium glutamate (MSG), which induces neonatal neuro-intoxication, causing hypothalamic lesions in the arcuate nucleus and neuroendocrine alterations such as hyperinsulinaemia and increased adiposity, among other effects. MSG treatment of animals has been reported to be a suitable model to study metabolic dysfunction [10-13].

The aim of the present work was to evaluate whether obese adult rats that were chronically treated with an antidiabetic drug, glibenclamide, exhibit resistance to rodent breast carcinoma (Walker-256 tumour) growth. 


\section{Cellular Physiology Cell Physiol Biochem 2017;42:81-90

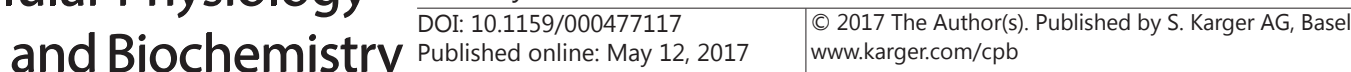

da Silva Franco et al.: Sulphonylurea Attenuates Walker Tumour Growth

\section{Material and Methods}

\section{Animals and experimental groups}

To induce the obese and pre-diabetic rat model, during the first 5 days of life, neonatal male Wistar rats were subcutaneously injected with MSG (Sigma-Aldrich®, St. Louis, MO, USA) at a dose of $4 \mathrm{mg} / \mathrm{kg}$ body weight (bw). Control animals received injections of an equimolar saline solution $[14,15]$.

At 21 days old, the male Wistar rats were divided into four groups: control and MSG, both treated with or without Gli.

During all procedures, animals were kept under controlled temperature conditions $\left(23 \pm 2^{\circ} \mathrm{C}\right)$ and a light/dark cycle of $12 \mathrm{~h}$ with ad libitum access to water and a standard diet (Nuvital ${ }^{\circledR}$, Curitiba, PR, Brazil). The Ethics Committee on Animal Use of the State University of Maringá approved the protocols.

\section{Experimental groups and Gli treatment}

To evaluate the potential of chronic Gli treatment as a preventive strategy against tumour growth, we administered the treatment by gavage once a day from weaning until 100 days of age. A batch of animals from both the control and MSG groups was treated with Gli (Glibenclamide, Medley, Brazil), which was dissolved in water, at a dose of $2 \mathrm{mg} / \mathrm{kg}$ of bw, and another batch of animals from the control and MSG groups received water. The drug dose used in the current protocol was previously tested in rats [16]. Twenty-four hours after the last glibenclamide gavage, animals from both groups, control and MSG, were used in the subsequent experimental procedure, in which a portion of the animals were inoculated with tumour cells. Figure 1 summarizes the experimental protocols.

\section{Inoculation of Walker-256 cells}

The Walker-256 tumour is a well-established experimental model that is often used to study tumour growth. This tumour was first described in 1928 by George Walker as a spontaneous carcinosarcoma from the mammary gland of rats [17]. Since then, the Walker-256 tumour has been perpetuated by various techniques.

In our laboratory, Walker-256 cells, kindly provided by the Laboratory of Cellular Metabolism Physiology (Federal University of Parana, Brazil), have been maintained in the intraperitoneal cavity of Wistar rats (ascitic form) [18] through weekly passages, every 7 days, by aseptic intraperitoneal injection of $1.0 \times 10^{6}$ cells per rat. After 7 days of ascitic growth, the peritoneal exudate is withdrawn and subjected

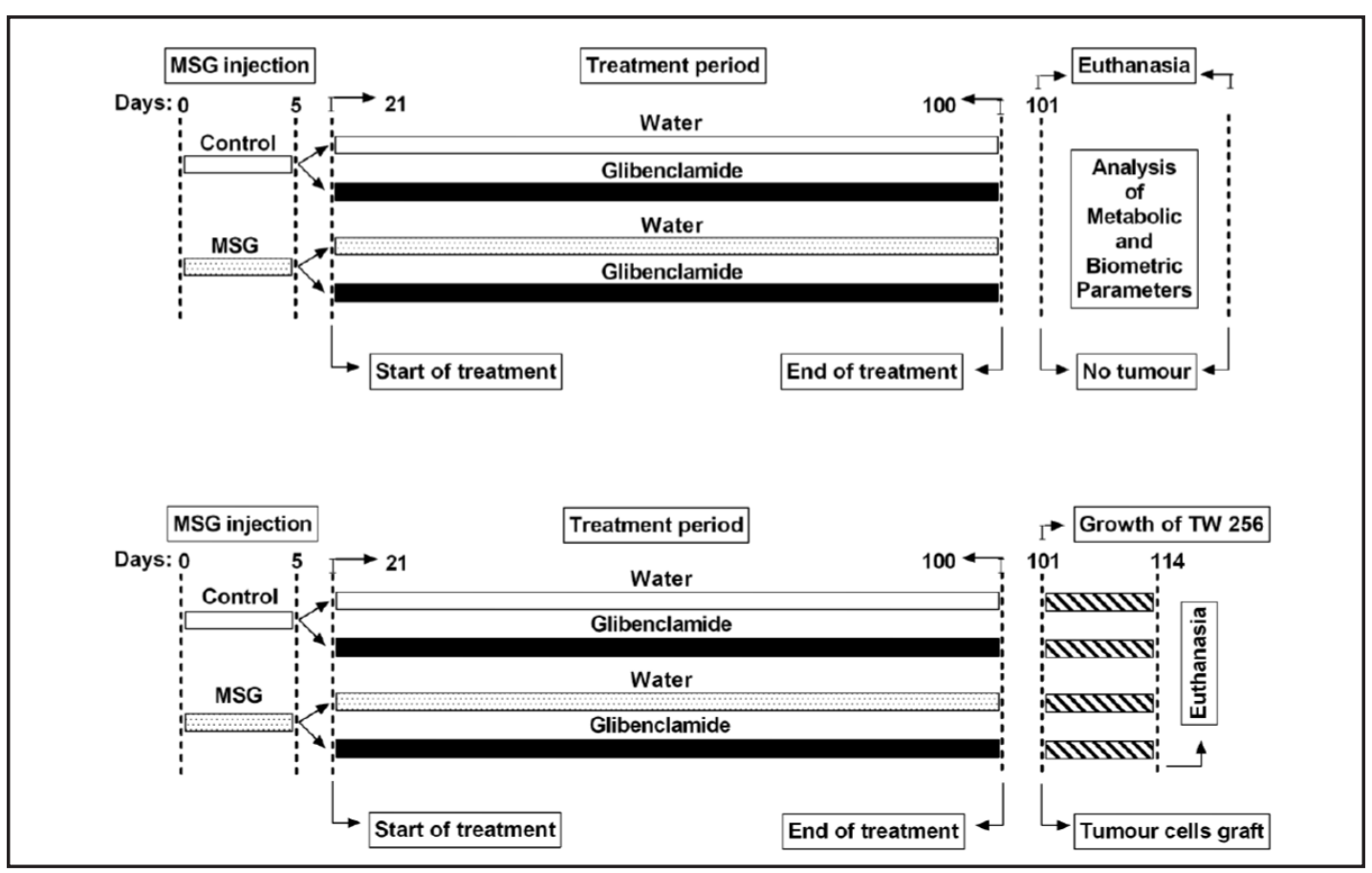

Fig. 1. Schematic representation of the experimental protocol. 


\section{Cellular Physiology Cell Physiol Biochem 2017;42:81-90

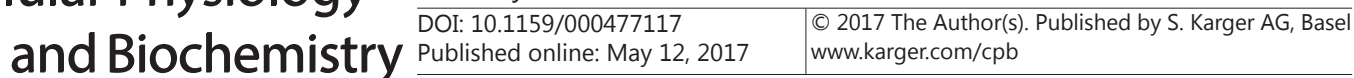

da Silva Franco et al.: Sulphonylurea Attenuates Walker Tumour Growth

to differential centrifugation at $4^{\circ} \mathrm{C}$ to obtain tumour cells. These cells are resuspended in phosphatebuffered saline (PBS; $16.5 \mathrm{mmol} \mathrm{l}^{-1}$ phosphate, $137 \mathrm{mmol} \mathrm{l}^{-1} \mathrm{NaCl}$ and $2.7 \mathrm{mmol} \mathrm{l}^{-1} \mathrm{KCl}, \mathrm{pH}$ 7.4). Cell viability is evaluated using the trypan blue exclusion method.

At the end of the treatment period, the 101-day-old animals from each experimental group were inoculated subcutaneously with $8.0 \times 10^{7}$ viable tumour cells/animal in the right rear flank $[19,20]$. The inoculation of the Walker-256 tumour cells was performed $24 \mathrm{~h}$ after the end of treatment with Gli. After 14 days of tumour inoculation, animals were euthanized for blood and tissue collection. Figure 1 summarizes the experimental protocols.

\section{Obesity assessment}

Obesity was assessed based on bw and nasoanal length (NAL), which was used to calculate the rodent body mass index, or Lee index, using the following equation: Lee index $=$ (body weight $[\mathrm{g}]^{1 / 3} / \mathrm{NAL}[\mathrm{cm}]$ ) $\mathrm{x} 100$ [21]. Retroperitoneal (RET), epididymal (EPI) and brown (BAT) adipose tissues were removed and weighed to estimate corporal adipose tissue.

\section{Analysis of metabolic and biometric parameters}

During the 14 days of tumour growth, body weight and food intake of all the groups were evaluated. After 14 days of tumour cell inoculation and $12 \mathrm{~h}$ of fasting, animals from all groups were weighed and subsequently euthanized by decapitation, and blood samples were collected and centrifuged to obtain the plasma for further analysis. Glucose concentration was determined by the glucose oxidase method using a commercial kit (Gold Analisa ${ }^{\circledR}$, Belo Horizonte, MG, Brazil), and insulin levels were evaluated using a radioimmunoassay (RIA) with a gamma counter (2470 Wizard ${ }^{2}$ Automatic Gamma Counter, PerkinElmer). The intra- and interassay coefficients of variation were $12.2 \%$ and $9.8 \%$, respectively, for insulin. The detection limit for the insulin level was $0.006 \mathrm{ng} / \mathrm{ml}[22]$.

\section{Evaluation of cachexia}

The tumour mass was carefully dissected and weighed to calculate the percentage of body weight loss (BWL) using the following equation:

BWL (\%) = 100x (bwi - bwf + tm + gbw) / (bwi + gbw),

where bwi: initial body weight (g), bwf: final body weight (g) of rats with tumours; tm: tumour mass (g); and bwg: body weight gain (g) of rats without tumours during the 14 days of the experiment. The rats were considered cachectic when the BWL was higher than 10\% [19].

\section{Inmunohistochemical assay}

Tumour samples were fixed in $4 \%$ buffered paraformaldehyde, embedded in histological paraffin and sectioned $(5 \mu \mathrm{m})$ in non-serial cuts. The tissue sections were deparaffinized, rehydrated, blocked against endogenous peroxidase with a $3 \%$ hydrogen peroxide solution ([v/v]: $\mathrm{H}_{2} \mathrm{O}_{2}$ in methanol; $3 \mathrm{ml} / 97 \mathrm{ml}$ ) for 15 min, washed in $0.01 \mathrm{~mol} \mathrm{l}^{-1}$ phosphate-buffered saline (PBS, pH 7.4) and incubated with 10\% non-immune goat serum blocking solution for $10 \mathrm{~min}$. The sections were then incubated with a monoclonal primary antibody against proliferative nuclear cell antigen (PCNA) at a dilution of 1:100 (Zymed ${ }^{\circledR}$, San Francisco, CA, USA) for $60 \mathrm{~min}$. After the sections were washed ( $\left.0.01 \mathrm{~mol} \mathrm{l}^{-1} \mathrm{PBS}\right)$, they were incubated with biotinylated secondary antibody for $10 \mathrm{~min}$, washed, incubated with diaminobenzidine chromogenic solution (DAB) for $15 \mathrm{~min}$, washed and counterstained with haematoxylin. Analyses of PCNA-positive cells (brown nuclei) were performed using 40 digital images ( $\times 400$ magnification) from each animal ( $n=5$ animals/group), for a total of 200 images per group. The quantitative analyses were performed by calculating the percentage of PCNA-positive cells over the total cell number for each digital image. Cell counts were performed manually using Image-Pro Plus 4.5 software (Media Cybernetics, Silver Spring, MD, USA).

\section{Statistical analysis}

Data are given as the mean \pm SEM and were subjected to variance analysis (one-way ANOVA) followed by Bonferroni's test. A p value of less than 0.05 was considered statistically significant. Tests were performed using GraphPad Prism version 6.01 for Windows (GraphPad Software, La Jolla, CA, USA). 
da Silva Franco et al.: Sulphonylurea Attenuates Walker Tumour Growth

\section{Results}

Effects of MSG and Gli on biometric parameters

Table 1 shows that neonatal MSG treatment caused a 30.8\% reduction in bw and a $15.8 \%$ reduction in body length compared to control rats $(\mathrm{p}<0.0001)$. However, chronic Gli treatment was not able to change these parameters in either control or MSG animals. MSG treatment induced a $12 \%$ increase in the Lee index $(p<0.0001)$, while Gli treatment provoked a decrease of $7 \%$ in the MSG rats ( $p<0.0001)$ without changes in control animals. Chronic Gli treatment and tumour grafts did not alter the final food intake between the groups. The RET, EPI and BAT weights were higher in the MSG group compared to the control group $(p<0.0001)$, whereas Gli treatment reduced the EPI and BAT fat pads $(p<0.0001)$.

\section{Effects of MSG and Gli on progression of cachexia}

The rate of cachexia was $19.5 \%$ and $13.6 \%$ in rats from the control and MSG groups, respectively. However, chronic Gli treatment decreased this parameter in the animals of groups C-Gli (16.0\%) and MSG-Gli (12.1\%), as shown in Figure 2 ( $<<0.0001)$.

\section{Effects of MSG and Gli on glucose homeostasis}

Figure 3 shows the fasting glycaemia and insulinaemia for all experimental groups. There was no difference in glycaemia among the control groups that were treated or untreated with Gli and inoculated or not with the Walker-256 tumour cells (Fig. 3A). However, the tumour-bearing MSG rats showed a decrease of $15 \%$ in the plasma glucose concentration compared to the MSG rats that were not grafted with tumour cells, as shown in Figure 3B ( $p<$ 0.0001). The fasting glycaemia was reduced in animals of both tumour-grafted MSG groups, regardless of the Gli treatment.

Table 1. Biometric parameters of the Control and MSG animals treated with or without Gli and without tumour cells. The data represent the mean \pm SEM obtained from 12 rats of each experimental group. Values within a row with unlike superscript letters were significantly different based on one-way ANOVA ( $\mathrm{p}<0.0001)$. ${ }^{\mathrm{a}}$ control; ${ }^{\mathrm{b}}$ control treated with Gli; ${ }^{\mathrm{c}} \mathrm{MSG}$; and ${ }^{\mathrm{d}}$ MSG treated with Gli. (Ret) retroperitoneal, (Epi) epididymal and (Bat) brown adipose tissues

\begin{tabular}{lllll}
\hline Biometric Parameters & Control a & Control-Gli b $^{\mathrm{M}}$ & MSG $^{\mathrm{c}}$ & MSG-Gli d \\
\hline Final Body Weight $(\mathrm{g})$ & $353.2 \pm 7.4^{\mathrm{cd}}$ & $342.4 \pm 10.8^{\mathrm{cd}}$ & $233.7 \pm 16.6^{\mathrm{ab}}$ & $270.7 \pm 8.5^{\mathrm{ab}}$ \\
Body Length $(\mathrm{cm})$ & $21.5 \pm 0.3^{\mathrm{cd}}$ & $21.3 \pm 0.4^{\mathrm{cd}}$ & $18.1 \pm 0.5^{\mathrm{ab}}$ & $18.5 \pm 0.2^{\mathrm{ab}}$ \\
Lee Index & $33.5 \pm 0.5^{\mathrm{c}}$ & $33.3 \pm 0.8^{\mathrm{c}}$ & $37.4 \pm 1.0^{\mathrm{abd}}$ & $34.0 \pm 0.4^{\mathrm{c}}$ \\
AUC Food Intake $(\mathrm{g} / 100 \mathrm{~g})$ & $82.0 \pm 3.87$ & $74.9 \pm 8.30$ & $81.9 \pm 9.40$ & $72.4 \pm 3.06$ \\
Ret Fat Pad $(\mathrm{g} / 100 \mathrm{~g})$ & $1.03 \pm 0.09^{\mathrm{cd}}$ & $1.08 \pm 0.09^{\mathrm{cd}}$ & $1.65 \pm 0.13^{\mathrm{ab}}$ & $1.67 \pm 0.08^{\mathrm{ab}}$ \\
Epi Fat Pad $(\mathrm{g} / 100 \mathrm{~g})$ & $0.92 \pm 0.05^{\mathrm{cd}}$ & $1.07 \pm 0.07^{\mathrm{cd}}$ & $2.13 \pm 0.06^{\mathrm{abd}}$ & $1.66 \pm 0.08^{\mathrm{abc}}$ \\
Bat Fat Pad $(\mathrm{g} / 100 \mathrm{~g})$ & $0.02 \pm 0.002^{\mathrm{cd}}$ & $0.03 \pm 0.002^{\mathrm{cd}}$ & $0.10 \pm 0.007^{\mathrm{abd}}$ & $0.06 \pm 0.003^{\mathrm{abc}}$
\end{tabular}

Fig. 2. Effect of Gli treatment on the percentage of cachexia. The bars represent the mean \pm SEM of the percentage of rats with a bw loss of more than $10 \%$. The letters over the bars represent statistically significant differences using one-way ANOVA ( $p<0.0001)$ among the groups. ${ }^{a}$ control; ${ }^{b}$ control treated with Gli; ${ }^{\mathrm{c}} \mathrm{MSG}$; and ${ }^{\mathrm{d}}$ MSG treated with Gli.

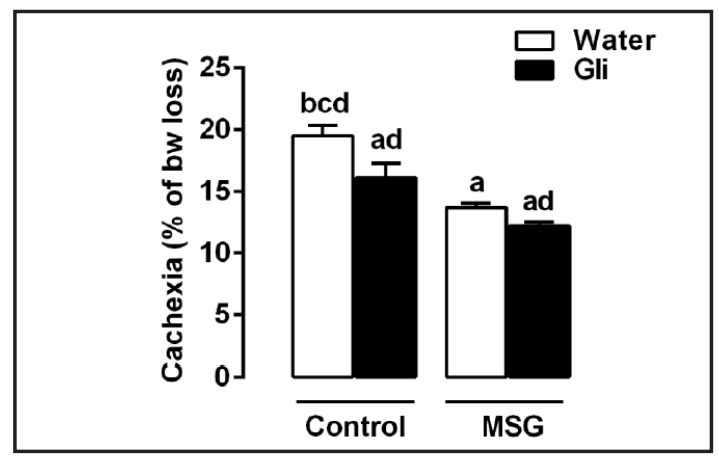


da Silva Franco et al.: Sulphonylurea Attenuates Walker Tumour Growth

Fig. 3. Effect of chronic Gli treatment on the fasting glycaemia and insulinaemia of the animals. The bars represent the mean \pm SEM of the fasting plasma glucose concentration in control rats (A) and MSG rats (B), healthy or with tumours, and fasting plasma insulin levels from control rats (C) and MSG rats (D), healthy or with tumours. The letters over the bars represent statistically significant differences using one-way ANOVA $(\mathrm{p}<0.0001)$ among the groups. ${ }^{\text {a }}$ control; ${ }^{b}$ control treated with Gli; ${ }^{\mathrm{c}}$ MSG; and ${ }^{\mathrm{d}}$ MSG treated with Gli.
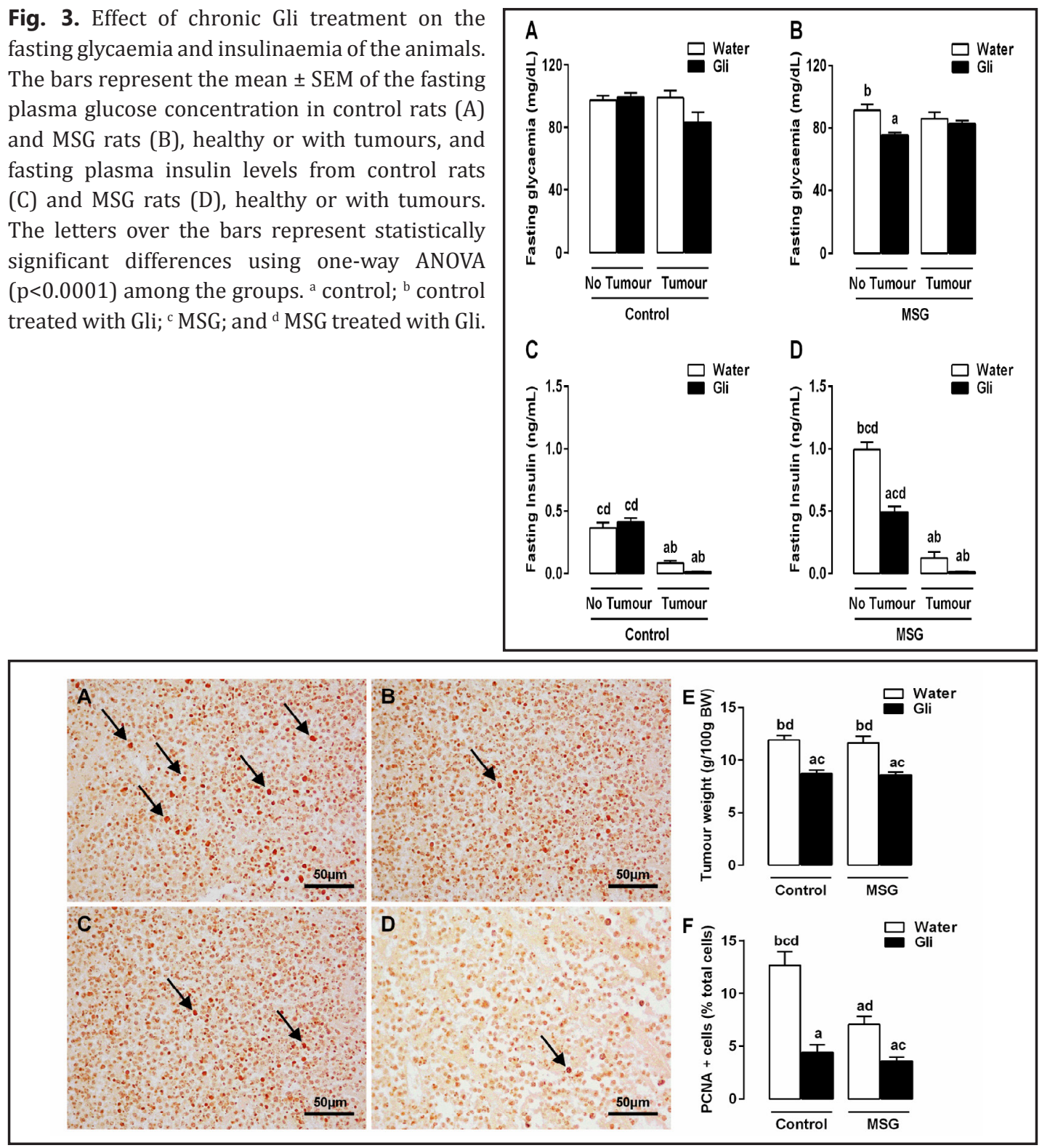

Fig. 4. Representative photomicrographs $(A-F, \times 400$ magnification) show Walker-256 tumour sections immunostained with an anti-PCNA antibody. (A) control group, (B) Gli-treated control group, (C) MSG group and (D) Gli-treated MSG group. Arrows in the images show nuclei immunolabelled for PCNA in the tumour (brown). (E) Tumour growth. (F) Quantitative analysis of the PCNA-positive cells. Data are presented as the mean \pm SEM, $p<0.05$. The letters over the bars represent statistically significant differences using one-way ANOVA $(\mathrm{p}<0.05)$ among the groups.

Fasting insulinaemia was increased 3-fold in the MSG animals compared with the control animals (Fig. 3C and 3D; $p<0.0001$ ). While chronic Gli treatment did not change fasting insulinaemia in the control animals, the treatment did cause a $60 \%$ decrease in the MSG rats $(p<0.0001)$. Tumour transplantation decreased the fasting plasma insulin levels in both the control ( $p<0.0001$, Fig. 3C) and MSG groups ( $<<0.0001$, Fig. 3D); however, there was a 4-fold reduction in the control rats and an 8-fold decrease in the MSG rats ( $p<0.0001)$. Tumour-grafted control and MSG animals treated with Gli showed decreases of 8- and 10fold in fasting insulinaemia, respectively, as also shown in Figure 3C and 3D $(\mathrm{p}<0.0001)$. 
da Silva Franco et al.: Sulphonylurea Attenuates Walker Tumour Growth

\section{Effects of MSG and Gli on growth and histological analysis of Walker-256 tumours}

The tumour growth was attenuated by approximately $27 \%$ in Gli-treated animals from both groups, as shown in Figure 4E $(\mathrm{p}<0.0001)$.

The histological examination of the tumour tissue revealed a large reduction in PCNApositive cells in the Gli-treated control group, MSG group and Gli-treated MSG group compared to the control group (Fig. 4A - D). Furthermore, the quantitative morphometrical analysis showed a significant reduction in PCNA-positive cells (Fig. 4F) in MSG rats and in both groups treated with Gli. As seen in Figure 4F, the number of immunolabelled PCNApositive cells was reduced by $65 \%$ in the control Gli-treated group and $44 \%$ in the MSG group compared to the control group ( $\mathrm{p}<0.0001$ and $\mathrm{p}<0.001$, respectively). In addition, Gli promoted a $49 \%$ reduction of PCNA-positive cells in the Gli-treated MSG group in relation to the MSG group (Fig. 4E; p<0.05).

\section{Discussion}

The prediabetic obese rats displayed moderate hyperglycaemia and severe hyperinsulinaemia, similar to previous studies [23, 24]. In addition, chronic Gli treatment improved the metabolism of prediabetic obese MSG-rats. For example, Gli treatment normalized the tissue insulin sensitivity and glucose tolerance, suppressed the fasting hyperinsulinaemia and reduced adipose tissue accretion, effects that were previously reported by other studies with antidiabetic drugs $[25,26]$. Gli treatment did not change the biometric and metabolic parameters of control rats.

It has been show that Gli was able to inhibit growth in human and rodents tumour cell culture [27]. In the current study, Gli previous treatment was also inhibited tumour growth in rats bearing Walker-256 cancer cells. The literature shows that Gli inhibits cell growth by inducing G0/G1 arrest in the human breast cancer, cell line mda-mb-231 [28-30]. Indeed, for the first time, our findings show that chronic treatment with Gli is capable of protecting both control and prediabetic obese MSG-rats against tumour growth, even when Gli treatment was stopped one day before tumour cell grafts. Our results suggest that Gli has an antiproliferative effect. Using another antidiabetic drug, metformin, our group recently demonstrated that Walker-256 tumour growth was inhibited [26]. In the present study, the rats did not receive Gli during tumour growth. Tumour cells were grafted $24 \mathrm{~h}$ after the last dose of Gli treatment, which implies that no traces of the antihyperglycaemic drug could be found in the blood stream of the rats. According to other studies, the Gli plasma elimination

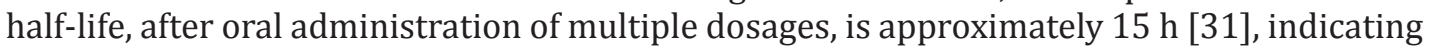
that Gli could protect the organism against tumour growth.

Studies have shown that rats grafted with Walker-256 tumours display low levels of plasma insulin and decreased glucose-induced insulin secretion in pancreatic $\beta$ cells $[32,33]$. In the present work, Walker-256 tumour growth decreased insulin levels 4-fold in control rats and 8-fold in prediabetic obese rats, which is in agreement with previous reports [26, 32, 33]. Tumour requires lot of energy consuming very rapidly blood glucose. Like other cancer cells Walker-256 need anaerobic sources and it induces insulin resistance and at same time inhibits insulin secretion to guarantee that mostly of glucose available will be feeding tumour. Cachexia observed in rats bearing Walker-256 tumour is metabolic expression of low insulin blood levels [33]. As can be observed our results show that rats bearing tumour exhibit very low insulin blood concentration, even glibenclamide treated ones. It is surprizing that glucose levels are unchanged in those conditions, it means peripheral tissues from rats grafted with Walker256 tumour present reduction of glucose uptake regarding, ungrafted ones [26, 32, 33]. Regarding those observation, including insulin tissues resistance of tumour-bearing rats, it was expected hyperglycaemia; however, glucose levels are maintained similar to rat that were not transplanted with tumoral cells. It can be suggested that exceeding glucose is used by the tumour cells.

The magnitude of tumour growth was the same in both prediabetic obese MSG-rats and the control group, which suggests that the insulin decrease did not alter the tumour 
aggressiveness. We also cannot attribute the anti-tumour effects of Gli to the decrease in insulin, considering that the magnitude of growth inhibition was the same in both groups.

Our results show that the population of PCNA-positive cells in the Walker-256 tumour cells was greatly reduced in both the control and MSG groups treated with Gli compared with the control group, suggesting that Gli exerts a direct inhibitory effect on tumour growth. One explanation for this direct effect is the blocking of $\mathrm{K}_{\text {ATP }}$ channels [7, 34]. However, the number of PCNA-positive cells was also markedly reduced in the tumours of prediabetic MSG-obese rats not treated with Gli.

It has been show that administration of MSG to newborn rodents produces hypothalamic lesions in the arcuate nucleus causing obesity, hyperinsulinaemia, insulin resistance, low sympathetic activity, high parasympathetic tone, increased DNA synthesis in some organs and the stimulation of cell proliferation. [35, 36]. However, studies have reported that the turnover of some cells in MSG-treated rats was decelerated [35]. These findings allow us to suggest that the cell turnover of the Walker-256 tumour may have decreased in grafted rats with hypothalamic obesity.

Several studies have demonstrated the effects of Gli on tumour growth arrest in different cancer types [27, 28, 37]. It has been shown that different subtypes of potassium channels are involved in normal and malignant cell proliferation [38]. Moreover, previous studies showed that Gli has a wide range of anti-inflammatory effects $[39,40]$. It has been shown that compounds with anti-inflammatory action also present anticancer effect [41].

Furthermore, the sulphonylurea receptor (SUR) is a regulatory subunit of ATP-sensitive potassium channels and belongs to the ATP-binding cassette (ABC) protein superfamily, a group of transmembrane proteins that utilize ATP to transport substrates, such as metabolic products, lipids, sterols, and drugs, across extra- and intracellular membranes. Thus, Gli can bind to SUR and block the activity of numerous $A B C$ transporters, including the multidrug transporter involved in anticancer drug resistance, which may be a promising target for anticancer therapy $[7,28]$.

Gli is a low-cost drug widely used for the treatment of type 2 diabetes, and to the best of our knowledge, there are no published studies reporting the toxicity of Gli when it is used at therapeutic concentrations. Recently, our group published results that indicate no cytotoxicity and genotoxicity effect of metformin and glibenclamide in eukaryotic cells. These results, at least, suggest that these antidiabetic drugs can be used in chemotherapy to cancer tumours, without risk to aggravate the disease, such as secondary cancer [42, 43].

The results showed in the present study are consistent to conclude that previous treatment with Gli, prior to the tumour cell grafts and/or their growth, induced an imprinted effect that attenuates the cancer growth independent of the positive effects on metabolism, indicating a direct effect of Gli on the Walker-256 tumour growth. Independent of mechanisms of action, Gli might be faced as potential prophylactic anticancer therapy.

\section{Acknowledgements}

This work was supported by the Brazilian Federal Foundation, the Conselho Nacional de Desenvolvimento Científico e Tecnológico (CNPq), the Coordenação de Aperfeiçoamento de Pessoal de Nível Superior (CAPES) and the Paraná Science Foundation (Fundação Araucária).

\section{Disclosure Statement}

The authors declare no conflicts of interest associated with this manuscript.

\section{References}

1 Sommer I, Griebler U, Mahlknecht P, Thaler K, Bouskill K, Gartlehner G, Mendis S: Socioeconomic inequalities in non-communicable diseases and their risk factors: An overview of systematic reviews. BMC Public Health 2015;15:914. 


\section{Cellular Physiology Cell Physiol Biochem 2017;42:81-90 and Biochemistry PublisherontIne: IVlay L2, $2017 \quad \begin{aligned} & \text { DOI: 10.1159/000477117 } 2017 \text { The Author(s). Published by S. Karger AG, Basel } \\ & \text { www.karger.com/cpb }\end{aligned}$}

da Silva Franco et al.: Sulphonylurea Attenuates Walker Tumour Growth

2 Wang L-P, Jiang Y, Yang H, Peng C, Zhang C, Tao X, Xie H-H: Combination therapy of nifedipine and sulphonylureas exhibits a mutual antagonistic effect on the endothelial cell dysfunction induced by hyperglycemia linked to vascular disease. Cell Physiol Biochem 2016;38:2337-2347.

-3 Giovannucci E, Harlan DM, Archer MC, Bergenstal RM, Gapstur SM, Habel LA, Pollak M, Regensteiner JG, Yee D: Diabetes and cancer: A consensus report. Diabetes Care 2010;33:1674-1685.

4 Kasper JS, Giovannucci E: A meta-analysis of diabetes mellitus and the risk of prostate cancer. Cancer Epidemiol Biomarkers Prev 2006;15:2056-2062.

-5 Steinberger J, Daniels SR, American Heart Association Atherosclerosis H, Obesity in the Young C, American Heart Association Diabetes C: Obesity, insulin resistance, diabetes, and cardiovascular risk in children: An american heart association scientific statement from the atherosclerosis, hypertension, and obesity in the young committee (council on cardiovascular disease in the young) and the diabetes committee (council on nutrition, physical activity, and metabolism). Circulation 2003;107:1448-1453.

6 Vigneri P, Frasca F, Sciacca L, Pandini G, Vigneri R: Diabetes and cancer. Endocr Relat Cancer 2009;16:11031123.

7 Pasello G, Urso L, Conte P, Favaretto A: Effects of sulfonylureas on tumor growth: A review of the literature. Oncologist 2013;18:1118-1125.

8 Patane G, Piro S, Anello M, Rabuazzo AM, Vigneri R, Purrello F: Exposure to glibenclamide increases rat beta cells sensitivity to glucose. Br J Pharmacol 2000;129:887-892.

-9 Li D, Yeung SC, Hassan MM, Konopleva M, Abbruzzese JL: Antidiabetic therapies affect risk of pancreatic cancer. Gastroenterology 2009;137:482-488.

10 Andreazzi AE, Grassiolli S, Marangon PB, Martins AG, de Oliveira JC, Torrezan R, Gravena C, Garcia RM, Mathias PC: Impaired sympathoadrenal axis function contributes to enhanced insulin secretion in prediabetic obese rats. Exp Diabetes Res 2011;2011:947917.

-11 Campos-Sepulveda AE, Ayala-Guerrero F, Rubio-Poo C, Roman-Ramos R: Neonatal monosodium glutamate increases ethanol susceptibility effects in adult mice. Proc West Pharmacol Soc 2002;45:44-46.

$\checkmark 12$ Collison KS, Makhoul NJ, Zaidi MZ, Al-Rabiah R, Inglis A, Andres BL, Ubungen R, Shoukri M, Al-Mohanna FA: Interactive effects of neonatal exposure to monosodium glutamate and aspartame on glucose homeostasis. Nutr Metab (Lond) 2012;9:58.

13 Nagata M, Suzuki W, Iizuka S, Tabuchi M, Maruyama H, Takeda S, Aburada M, Miyamoto K: Type 2 diabetes mellitus in obese mouse model induced by monosodium glutamate. Exp Anim 2006;55:109-115.

14 Hirata AE, Andrade IS, Vaskevicius P, Dolnikoff MS: Monosodium glutamate (msg)-obese rats develop glucose intolerance and insulin resistance to peripheral glucose uptake. Braz J Med Biol Res 1997;30:671674.

15 Olney JW, Sharpe LG: Brain lesions in an infant rhesus monkey treated with monsodium glutamate. Science 1969;166:386-388.

16 Sokolovska J, Isajevs S, Sugoka O, Sharipova J, Paramonova N, Isajeva D, Rostoka E, Sjakste T, Kalvinsh I, Sjakste N: Comparison of the effects of glibenclamide on metabolic parameters, glut1 expression, and liver injury in rats with severe and mild streptozotocin-induced diabetes mellitus. Medicina (Kaunas) 2012;48:532-543.

17 Earle WR: A study of the walker rat mammary carcinoma 256, in vivo and in vitro. Am J Cancer 1935;24:566-612.

18 Agostino D, Cliffton EE: The growth and transplantability of the carcinosarcoma of walker 256 in the ascitic form. Experientia 1968;24:166-167.

19 Cassolla P, Moreira CC, Liboni TF, Zaia CT, Borba-Murad GR, Bazotte RB, de Souza HM: Changes in blood metabolic parameters during the development of walker-256 tumour-induced cachexia in rats are not caused by decreased food intake. Cell Biochem Funct 2012;30:265-270.

20 de Souza CO, Kurauti MA, Silva Fde F, de Morais H, Curi R, Hirabara SM, Rosa Neto JC, de Souza HM: Celecoxib and ibuprofen restore the atp content and the gluconeogenesis activity in the liver of walker-256 tumor-bearing rats. Cell Physiol Biochem 2015;36:1659-1669.

21 Bernardis LL, Patterson BD: Correlation between 'lee index' and carcass fat content in weanling and adult female rats with hypothalamic lesions. J Endocrinol 1968;40:527-528.

-22 Scott AM, Atwater I, Rojas E: A method for the simultaneous measurement of insulin release and b cell membrane potential in single mouse islets of langerhans. Diabetologia 1981;21:470-475. 


\section{Cellular Physiology Cell Physiol Biochem 2017;42:81-90

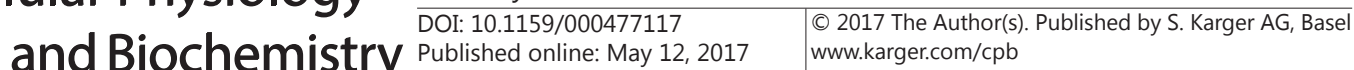

da Silva Franco et al.: Sulphonylurea Attenuates Walker Tumour Growth

-23 Balbo SL, Grassiolli S, Ribeiro RA, Bonfleur ML, Gravena C, Brito Mdo N, Andreazzi AE, Mathias PC, Torrezan R: Fat storage is partially dependent on vagal activity and insulin secretion of hypothalamic obese rat. Endocrine 2007;31:142-148.

24 Miranda RA, Branco RC, Gravena C, Barella LF, da Silva Franco CC, Andreazzi AE, de Oliveira JC, Picinato MC, de Freitas Mathias PC: Swim training of monosodium l-glutamate-obese mice improves the impaired insulin receptor tyrosine phosphorylation in pancreatic islets. Endocrine 2013;43:571-578.

25 Lobato NS, Filgueira FP, Hagihara GN, Akamine EH, Pariz JR, Tostes RC, Carvalho MH, Fortes ZB: Improvement of metabolic parameters and vascular function by metformin in obese non-diabetic rats. Life Sci 2012;90:228-235.

-26 Franco CC, Miranda RA, de Oliveira JC, Barella LF, Agostinho AR, Prates KV, Malta A, Trombini AB, Torrezan R, Gravena C, Tofolo LP, de Sant'Anna JR, de Castro Prado MA, de Souza CO, de Souza HM, Beraldi EJ, Mathias PC: Protective effect of metformin against walker 256 tumor growth is not dependent on metabolism improvement. Cell Physiol Biochem 2014;34:1920-1932.

27 Malhi H, Irani AN, Rajvanshi P, Suadicani SO, Spray DC, McDonald TV, Gupta S: Katp channels regulate mitogenically induced proliferation in primary rat hepatocytes and human liver cell lines. Implications for liver growth control and potential therapeutic targeting. J Biol Chem 2000;275:26050-26057.

28 Nunez M, Medina V, Cricco G, Croci M, Cocca C, Rivera E, Bergoc R, Martin G: Glibenclamide inhibits cell growth by inducing g0/g1 arrest in the human breast cancer cell line mda-mb-231. BMC Pharmacol Toxicol 2013;14:6.

29 Cocca C, Martin G, Nunez M, Gutierrez A, Cricco G, Mohamad N, Medina V, Croci M, Crescenti E, Rivera E, Bergoc R: Effect of glibenclamide on n-nitroso-n-methylurea-induced mammary tumors in diabetic and nondiabetic rats. Oncol Res 2005;15:301-311.

-30 Qian L, Zhang S, Xu L, Peng Y: Endoplasmic reticulum stress in beta cells: Latent mechanism of secondary sulfonylurea failure in type 2 diabetes? Med Hypotheses 2008;71:889-891.

-31 Jonsson A, Rydberg T, Sterner G, Melander A: Pharmacokinetics of glibenclamide and its metabolites in diabetic patients with impaired renal function. Eur J Clin Pharmacol 1998;53:429-435.

-32 Fernandes LC, Machado UF, Nogueira CR, Carpinelli AR, Curi R: Insulin secretion in walker 256 tumor cachexia. Am J Physiol 1990;258:E1033-1036.

33 el Razi Neto S, Zorn TM, Curi R, Carpinelli AR: Impairment of insulin secretion in pancreatic islets isolated from walker 256 tumor-bearing rats. Am J Physiol 1996;271:C804-809.

34 Kim JA, Kang YS, Lee SH, Lee EH, Yoo BH, Lee YS: Glibenclamide induces apoptosis through inhibition of cystic fibrosis transmembrane conductance regulator (cftr) cl(-) channels and intracellular ca(2+) release in hepg2 human hepatoblastoma cells. Biochem Biophys Res Commun 1999;261:682-688.

-35 Nakayama D, Magami Y, Azuma T, Inokuchi H, Furukawa M, Ohyashiki J, Yoshimoto T, Mizuguchi J, Moriyasu F, Kawai K, Hattori T: Turnover of acinar and islet cells in the pancreas of monosodium glutamate-treated obese mice. Obes Res 2003;11:87-94.

-36 Kiba T, Tanaka K, Numata K, Hoshino M, Misugi K, Inoue S: Ventromedial hypothalamic lesion-induced vagal hyperactivity stimulates rat pancreatic cell proliferation. Gastroenterology 1996;110:885-893.

-37 Wondergem R, Cregan M, Strickler L, Miller R, Suttles J: Membrane potassium channels and human bladder tumor cells: Ii. Growth properties. J Membr Biol 1998;161:257-262.

-38 Pardo LA: Voltage-gated potassium channels in cell proliferation. Physiology (Bethesda) 2004;19:285-292.

-39 Simard JM, Geng Z, Woo SK, Ivanova S, Tosun C, Melnichenko L, Gerzanich V: Glibenclamide reduces inflammation, vasogenic edema, and caspase-3 activation after subarachnoid hemorrhage. J Cereb Blood Flow Metab 2009;29:317-330.

40 Koh GC, Maude RR, Schreiber MF, Limmathurotsakul D, Wiersinga WJ, Wuthiekanun V, Lee SJ, Mahavanakul W, Chaowagul W, Chierakul W, White NJ, van der Poll T, Day NP, Dougan G, Peacock SJ: Glyburide is antiinflammatory and associated with reduced mortality in melioidosis. Clin Infect Dis 2011;52:717-725.

41 Rauf A, Imran M, Butt MS, Nadeem M, Peters DG, Mubarak MS: Resveratrol as an anticancer agent: A review. Crit Rev Food Sci Nutr 2016:0.

42 de Sant'Anna JR, Franco CC, Mathias PC, de Castro-Prado MA: Assessment of in vivo and in vitro genotoxicity of glibenclamide in eukaryotic cells. PLoS One 2015;10:e0120675.

43 Sant'Anna JR, Yajima JP, Rosada LJ, Franco CC, Prioli AJ, Della-Rosa VA, Mathias PC, Castro-Prado MA: Metformin's performance in in vitro and in vivo genetic toxicology studies. Exp Biol Med (Maywood) 2013;238:803-810. 